\title{
Fungal contamination and chemical assessment of Iranian Doogh marketed in Hamadan, Iran
}

Abbas Ali Sari ${ }^{1}$, Negar Sasanian ${ }^{1}$, Mohammadreza Pajohi-Alamoti ${ }^{1}$, Nazanin Sasanian ${ }^{2}$

\author{
Journal of Research \& Health \\ Social Development \& Health Promotion \\ Research Center \\ Vol. 8, No. 1, Jan \& Feb 2018 \\ Pages: 47- 51 \\ DOI: 10.29252/acadpub.jrh.8.1.47 \\ Original Article
}

1. Department of Food Hygiene and Quality Control, Faculty of Veterinary Science, Bu-Ali Sina University, Hamedan, Iran

2. Department of Food Science and Technology, National Nutrition and Food Technology Research Institute, Faculty of Nutrition Sciences and Food Technology, Shahid Beheshti University of Medical Sciences, Tehran, Iran

Correspondence to: Abbas Ali Sari, Department of Food Hygiene and Quality Control, Faculty of Veterinary Science, Bu-Ali Sina University, Hamedan, Iran

Email: sari_abas@yahoo.com

Received: 6 Jun 2016

Accepted: 25 Sep 2016

How to cite this article: Sari AA, Sasanian N, Pajohi-Alamoti M, Sasanian N. Fungal contamination and chemical assessment of Iranian Doogh marketed in Hamadan, Iran. $J$ Research \& Health2018; 8(1): 47- 51 .

\begin{abstract}
Doogh is an Iranian traditional dairy-based drink product formally identified as Iranian national drink. This fermented acidified drink has high nutritional value and pleasant organoleptic properties. Samples $(n=120)$ collected from both industrial and traditional Doogh retail stores in Hamadan in 2015 were analyzed for total solids (\%), pH, titratable acidity, salt (\%), mold and yeasts count (cfu/ml) according to the Iranian National Standards (no. 2453). Results showed that $100 \%$ and $24 \%$ of the traditional and industrial Doogh samples had fungal contamination over than $100 \mathrm{cfu} / \mathrm{ml}$, respectively. Moreover, the mean values of titratable acidity, $\mathrm{pH}$, salt, and total solids showed a significant between-group difference. According to this study, employing hygiene programs regarding the production processes is highly recommended.
\end{abstract}

Keywords: Chemical, Contamination, Dairy, Fungal, Hamadan

\section{Introduction}

Doogh as a native and traditional Iranian fermented drink has high value of nutrients and therapeutic properties. This product is also consumed in other countries such as Azerbaijan, Turkey, Armenia, Iraq, Syria, the Balkans, and to a lesser extent in other countries of the Middle East and central Asia [1]. This dairy-based drink is usually manufactured by mixing water, salt, and yoghurt, and acidified by fermentative bacteria including Streptococcus thermophilus and Lactobacillus delbrueckii ssp. bulgaricus. Chemical properties of Doogh consist of nonfat milk solids (minimum $3.2 \% \mathrm{w} / \mathrm{w}$ ), milk fat (maximum $50 \%$ of total dry non-fat in the final product), salt $(0.2-1.0 \% \mathrm{w} / \mathrm{w})$, and natural or natural identical flavoring compounds with a maximum $\mathrm{pH}$ of 4.5. Carbon dioxide (minimum $0.4 \% \mathrm{w} / \mathrm{w}$ ) may be artificially or naturally (through fermentation) added to the product $[1,2]$. Doogh have many salutary effects, including improving lactose digestion in lactose intolerance individuals, lowering serum cholesterol levels, and stimulating the immune system [3].

Nowadays, due to the increased public awareness about the harmful effects of some carbonated beverages, the consumption of this product has increased by about $40 \%$ [4]. One of the main problems in manufacturing plants is fungal contamination of dairy fermented products. Therefore, it causes undesirable features such as bitter taste, swelling, decreased 
shelf life, and lowered consumer acceptance $[5,6]$. Molds present in air, water, soil, walls, floors, ceilings, raw ingredients, packaging materials, and plant equipment; thus, unsuitable sanitizing programs increase the risk of fungal contamination in dairy products.

Control of fungal contamination in dairy products puts emphasis on good hygiene practices during production processes like packaging atmosphere and good air-filtration systems that lead to the reduction of the mold spores level in dairy plants [7]. Because of low $\mathrm{pH}$, cultured milk products such as fermented milk, yogurt, drinking yogurt, cottage cheese, cream cheese, etc. provide ideal media for the proliferation of molds and yeasts. These microorganisms are able to grow in a wide range of $\mathrm{pH}$ accordingly; they are normally able to spoil dairy products with a low $\mathrm{pH}$. On the other hand, some microorganisms belonging to the bacterial families (i.e., Bacillaceae, Enterobacteriaceae, and Pseudomonaceae) cannot proliferate in these conditions [8]. In a study conducted by Sperber and Doyle, it was shown that galactose, which is fermented by yeasts such as Saccharomyces cerevisiae and Hansenula anomala, has an important role in the spoilage of yogurt [9]. It is now well established from a variety of studies that Acid-tolerant, psychrotrophic, fermentative yeasts may be able to grow in yoghurt and cause blowing due to $\mathrm{CO}_{2}$ production. Species of Candida, Saccharomyces, Pichia, Rhodotorula, Kluyveromyces, and Torulopsis have been isolated from blown packs of yoghurt [10]. Furthermore, growth of species of Mucor, Aspergillus, Rhizopus, Alternaria, and Penicillium can occur in the product during retail storage, leading to the production of mycelia mats or buttons and visible spoilage. There are a large number of published studies describing the role of mold spores in the contamination of yoghurt by airborne dust particles, packaging, and added ingredients as well as through poor hygiene [11].

Microbiological analysis of bottled commercial and homemade ayran sold in Ankara and Kars in Turkey revealed the presence of very high numbers of total coliforms, yeasts, and molds. Bottled ayran was found to be of higher quality than homemade ayran samples that this contamination could be due to the lack of satisfactory sanitary conditions and quality control during manufacturing the ayran [12]. Another study was conducted in Mashhad to determine microbial condition (i.e., total aerobic bacteria, coliforms, psychrophilic bacteria, Lactic Acid Bacteria (LAB), and yeast) of three dairy plants revealing that the quality of Doogh depends on quality of raw milk, effectiveness of heat treatment, microbiological quality of added ingredients, packaging materials, cleanliness of surfaces coming into contact with the Doogh, and efficiency of the plant sterilization [5]. The goal of this study was to evaluate fungal contamination and chemical analysis of industrial and traditional Doogh samples marketed in Hamadan, Iran.

\section{Method}

Sample preparation: Based on Iranian national standard (no. 2453), totally 120 Doogh samples consisted of 100 industrial samples from four commercial brands ( 25 samples per each) and 20 samples from traditional Doogh purchased from different areas of Hamadan city during 2014 were collected. After sampling, all the samples were transferred to the laboratory under refrigerated conditions and analyzed immediately.

Chemical analysis: Each sample was mixed to ensure homogeneity and then analyzed for $\mathrm{pH}$ value and titratable acidity. To measure $\mathrm{pH}$ value, first the $\mathrm{pH}$ meter was calibrated and then $\mathrm{pH}$ values of all samples were measured at room temperature using a digital $\mathrm{pH}$ meter (Hanna, Italy). To determine the titratable acidity, $10 \mathrm{ml}$ of samples were mixed with equal volume of distilled water. 3-4 drops of $0.5 \%$ phenolphthalein indicator was added and finally, the content was titrated with $0.1 \mathrm{~N} \mathrm{NaOH}$ solution [13]. Total solids and salt content were measured according to the method of Iranian National Standard no. 637. Microbiological analysis: To enumerate mold and yeasts, all samples were diluted tenfold serial dilution by $0.1 \%$ peptone water and then, 
$100 \mu \mathrm{l}$ from each dilution (10-1, 10-2, and 103) was poured on Sabouraud Chloramphenicol agar plates (Quelab Company, Canada) and inoculated with a sterile bent glass rod. Plates were incubated at $25^{\circ} \mathrm{C}$ for 3 to 5 days and then, they were examined for the presence of yeast and mold colonies. Finally, plates containing 15-150 colonies were counted. The number of colony-forming units in samples was calculated using below formula:

Yeast and Mold count $(\mathrm{cfu} / \mathrm{ml})=$ number of colonies/(volume plated $\times$ dilution factor)

Statistical analysis: Data management and analysis were performed using SPSS-20. In order to compare means, one-way ANOVA was run. In cases with a meaningful difference in means, Tukey test was performed to compare means between the groups. Differences with 95\% confidence level were considered significant $(\mathrm{p}<0.05)$.

\section{Results}

The results of chemical and microbiological analysis of Doogh samples are presented in Table 1 and 2, respectively. One-way ANOVA showed that the mean values of acidity, $\mathrm{pH}$, total solids, and salts between the samples had statistically significant differences $(\mathrm{p}=0.000$, $\mathrm{F}=265.05, \mathrm{~F}=504.81, \mathrm{~F}=116.4, \mathrm{~F}=254.55$, respectively). Moreover, Tukey test indicated that the mean values of acidity and salt were significantly higher in traditional samples than industrial samples $(p=0.000)$. On the other hand, the traditional samples had no statistically significant differences regarding $\mathrm{pH}$ and total solids than B samples ( $\mathrm{p}>0.05$ ). According to the Iranian national standard for Doogh, maximum acceptable limits of fungal contamination should be $100 \mathrm{cfu} / \mathrm{g}$ [1]. As can be seen from Table 2, $100 \%$ and $24 \%$ of the traditional and industrial Doogh samples had contamination level higher than the standard level. Mostly, among industrial Doogh samples, $32 \%$ of A samples were contaminated with molds and $64 \%$ of $\mathrm{D}$ samples were contaminated with yeasts.

\begin{tabular}{|c|c|c|c|c|c|c|c|c|c|c|c|c|c|}
\hline \multirow{2}{*}{$\begin{array}{c}\text { Sample } \\
\text { type }\end{array}$} & \multirow{2}{*}{$\begin{array}{l}\text { Sample } \\
\text { (N) }\end{array}$} & \multicolumn{3}{|c|}{ Acidity (\%) } & \multicolumn{3}{|c|}{$\mathrm{pH}$} & \multicolumn{3}{|c|}{ Total Solids (\%) } & \multicolumn{3}{|c|}{ Salt (\%) } \\
\hline & & Min & Max & Mean \pm SD & Min & Max & Mean \pm SD & Min & Max & Mean \pm SD & Min & Max & Mean \pm SD \\
\hline A & 25 & 0.46 & 0.67 & $0.51 \pm 0.08^{\mathrm{ab}}$ & 4.20 & 4.25 & $4.22 \pm 0.01^{\mathrm{a}}$ & 0.29 & 0.32 & $0.30 \pm 0.009^{\mathrm{a}}$ & 0.31 & 0.37 & $0.34 \pm 0.015^{\mathrm{a}}$ \\
\hline B & 25 & 0.50 & 0.55 & $0.51 \pm 0.51^{\mathrm{a}}$ & 3.20 & 3.52 & $3.46 \pm 0.09^{b}$ & 0.23 & 0.26 & $0.24 \pm 0.009^{b}$ & 0.29 & 0.32 & $0.30 \pm 0.01^{\mathrm{b}}$ \\
\hline $\mathrm{C}$ & 25 & 0.66 & 0.70 & $0.67 \pm 0.67^{\mathrm{c}}$ & 3.75 & 3.81 & $3.78 \pm 0.02^{\mathrm{c}}$ & 0.33 & 0.39 & $0.36 \pm 0.014^{\mathrm{c}}$ & 0.29 & 0.33 & $0.30 \pm 0.012^{\mathrm{b}}$ \\
\hline $\mathrm{D}$ & 25 & 0.40 & 0.50 & $0.44 \pm 0.03^{\mathrm{b}}$ & 4.20 & 4.27 & $4.23 \pm 0.02^{\mathrm{a}}$ & 0.25 & 0.30 & $0.28 \pm 0.014^{\mathrm{d}}$ & 0.28 & 0.33 & $0.31 \pm 0.012^{\mathrm{b}}$ \\
\hline E & 20 & 0.92 & 1.67 & $1.26 \pm 0.2^{\mathrm{d}}$ & 3.03 & 3.65 & $3.39 \pm 3.17^{\mathrm{b}}$ & 0.17 & 0.35 & $0.23 \pm 0.053^{b}$ & 0.40 & 0.61 & $0.50 \pm 0.057^{\mathrm{c}}$ \\
\hline
\end{tabular}

* a, b, c, d; industrial samples, E; traditional samples

In each columns, results with the same letters had no significant difference ( $p>0.05)$.

Table 2 Results of mold and yeast counts in the examined samples

\begin{tabular}{cccc}
\hline Sample type & $\begin{array}{c}\text { Sample } \\
(\mathrm{N})\end{array}$ & $\begin{array}{c}\text { Positive } \\
\text { samples } \\
\mathrm{N}(\%)\end{array}$ & $\begin{array}{c}\text { Mould and } \\
\text { yeast count } \\
\left(\log _{10} \pm \mathrm{SD}\right)\end{array}$ \\
\hline A & 25 & $8(32)$ & $2.56 \pm 0.25$ \\
B & 25 & 0 & $<1$ \\
C & 25 & 0 & $<1$ \\
D & 25 & $16(64)$ & $3.7 \pm 0.02$ \\
E & 20 & $20(100)$ & $5.09 \pm 0.72$ \\
\hline
\end{tabular}

\section{Discussion}

Due to its nutritional value and health properties, Doogh has a special status among dairy products in Iran. This study was conducted to evaluate the quality of Iranian industrial and traditional Doogh. In line with those of previous studies, the results indicated high fungal contamination in study samples while chemical quality was in accordance with Iranian National Standard. Noori and Keshavarzian in a study on the 
physicochemical properties of four Doogh samples showed that the mean values of $\mathrm{pH}$, acidity, and salt content were $3.53,0.81$, and $0.72 \%$, respectively [14]. Gulmez et al. in a similar study evaluated the microbiological quality of bottled and homemade ayran samples and indicated the presence of very high number of total coliforms, yeast, and molds. Moreover, they indicated that bottled ayran had higher quality than homemade ayran [12]. El-Diasty et al., in mycological examination of raw milk and yoghurt samples, reported that 80 and $50 \%$ of raw milk and yoghurt samples were contaminated, respectively [15]. Furthermore, Sangatash et al. showed that microbiological quality of Doogh depends on the quality of raw milk, the sufficient temperature during processing, microbiological quality of added ingredients, packaging materials, food contact surfaces, and control of sterilization in the plant [5]. Moreira et al. conducted a study on the fungal contamination of yoghurt samples and identified high levels of contamination by some species of yeasts like Debaryomyces hansenii, Saccharomyces cerevisiae, Mrakia frigida, Hansenula spp., Candida parapsilosis, Debaryomyces castellii, Candida maltose, and some species of filamentous fungi like Monilia and Penicillium species, which could be due to inadequate refrigeration of products [16]. In addition, the presence of fungi in examined yoghurt samples was demonstrated by Eman et al. that could be because of unsuitable preheating process during manufacturing and using undesirable sterilized plastic containers or inefficient cooling during storage [17]. Study of Fallahi and Madani in Isfahan revealed that $13.4 \%$ of Doogh samples had more fungal contamination than acceptable standard limits and main contaminant fungi were allocated to Penicillium spp. [18].

\section{Conclusion}

This project was undertaken to determine fungal contamination and some chemical analysis in industrial and traditional Doogh samples marketed in Hamadan, Iran. The most obvious finding to emerge from this study is that all traditional Doogh samples and $24 \%$ of industrial Doogh samples had fungal contamination while both traditional and industrial ones were in accordance with Iranian national standards. Further research should focus on determining the level of fungal contamination in places of production until sale markets in order to investigate the importance of distributing product. Considering the high fungal contamination of Doogh, it is recommended to apply good manufacturing practice (GMP) and HACCP program during production processes.

\section{Acknowledgments}

The authors express their sincere appreciation to Mrs. Zahra Nazari (Internal manager of food control laboratory, Bu-Ali Sina University, Hamadan, Iran).

\section{Contribution}

Study design: AAS

Data collection and analysis: NS, AAS

Manuscript preparation: AAS, MRP, NS

\section{Conflict of Interest}

"The authors declare that they have no competing interests.

\section{Funding}

The authors are grateful to Bu-Ali Sina University (Hamadan, Iran) for financial support (grant no.1542/94).

\section{References}

1- Institute of Standard and Industrial Researches of Iran (ISIRI), No: 2453, Doogh - Specifications and Test Method, 2nd revision 2008. Institute of Standard and Industrial Researches of Iran. Karaj, Iran.

2-Azarikia F, Abbasi S. On the stabilization mechanism of Doogh (Iranian yoghurt drink) bygum tragacanth. Food Hydrocoll2010; 24(4): 358-63.

3- Olson DW, Aryana KJ. An excessively high an excessively high Lactobacillus acidophilus inoculation level in yogurt lowers product quality during storage. LWT-Food Sci. Technol2008; 41(5): 911-8.

4- Vosough AS, Khomeyri M, Kashaninezhad M, Seyed MJ. Effects of mint extract on the viability of probiotic bacteria in a native Iranian dairy drink 
(doogh). Journal of Agricultural Sciences and Natural Resources2009; 16(1): 156-64.

5- Sangatash MM, Jamab MS, Karajian R, et al. Evaluation of microbiological contamination sources on swelling of Iranian yoghurt drink during production processes. J Food Res2011; 1: 45-55.

6- Rahimirad A. Incidence of potassium sorbate in Doogh (Iranian Yoghurt Drink) produced in west azerbayjan province of Iran. Int J Adv Biol Biom Res2014; 4(2): 336-41.

7- Loureiro V, Querol A. The prevalence and control of spoilage yeasts in foods and beverages. Trends Food Sci Tech1999; 10(11): 356-65.

8- Büchl NR, Seiler H. Yeasts and molds: Yeasts in milk and dairy products. In: Fuquay JW, ed. Encyclopedia of dairy sciences. San Diego: Academic press; 2011. pp: 744-53.

9- Sperber WH, Doyle MP. Compendium of the microbiological spoilage of foods and beverages, Food Microbiology and Food Safety. New York: Springer; 2009. 10- Jay JM, Loessner MJ, Golden DA. Modern food microbiology. New York: Springer; 2005.

11- Pitt JI, Hocking AD. Fungi and food spoilage. New York: Springer; 2009.

12- Gülmez M, Güven A, Sezer Ç, Duman B. Evaluation of microbiological and chemical quality of ayran samples marketed in Kars and Ankara cities in Turkey. Kafkas
Üniversitesi Veteriner Fakültesi Dergisi2003; 9(1): 4952.

13- Mortazavian AM, Khosrokhavar R, Rastegar H, Mortazaei GR. Effects of dry matter standardization order on biochemical and microbiological characteristics of freshly made probiotic doogh (Iranian fermented milk drink). Ital J Food Sci2010; 22(1): 98-104.

14- Noori A, Keshavarzian F, Mahmoudi S, Yousefi M, Nateghi L. Comparison of traditional Doogh (yogurt drinking) and Kashk characteristics (Two traditional Iranian dairy products). Eur J Exp Biol2013; 3(6): 252255.

15- El-Diasty EM, El-Kaseh RM. Microbiological monitoring of raw milk and yoghurt samples collected from El-Beida city. Arab J Biotech2009; 12(1): 57-64. 16- Moreira SR, Schwan RF, Carvalho EPD, Wheals AE. Isolation and identification of yeasts and filamentous fungi from yoghurts in Brazil. Braz $J$ Microbiol2001; 32(2): 117-22.

17- El-Diasty EM, El-Kaseh RM. Microbiological monitoring of raw milk and yoghurt samples collected from El-Beida city. Arab J Biotechnol2009; 12(1): 57-64. 18- Fallahi F, Madani M. Study of contamination of different dairy products distributed in Isfahan to saprophytic fungi. Biological Journal of Microorganism2014; 3(11): 59-70.

\footnotetext{
Copyright(C) 2016 ASP Ins. This open-access article is published under the terms of the Creative Commons Attribution-NonCommercial 4.0 International License which permits Share (copy and redistribute the material in any medium or format) and Adapt (remix, transform, and build upon the material) under the Attribution-NonCommercial terms.
} 